\section{Coffee-bean sign}

A n 85-year-old man with a history of tongue cancer presented to the emergency department with a 2 -day history of abdominal distension, pain and constipation. He had no fever or vomiting. A physical examination revealed a distended abdomen with decreased bowel sounds. A plain radiograph of the abdomen showed a markedly distended sigmoid loop with an inverted U-shape (Figure I), also known as the "coffeebean sign," consistent with sigmoid volvulus. A rubber drain tube was inserted through the rectum for decompression by use of a fiberscope.

Sigmoid volvulus is a potentially life-threatening condition. It is the third most common cause of colonic obstruction after cancer and diverticulitis, and it accounts for about $8 \%$ of intestinal obstructions. Proposed causes include anatomic variation, chronic constipation, neurologic disease and megacolon. Clinical presentation includes abdominal bloating, pain, vomiting, constipation and peritonitis. ${ }^{1}$ Conservative treatment options include decompression under fluoroscopy or endoscopy, and surgery may be required for failed decompression, recurrent volvulus or bowel ischemia. ${ }^{2}$

\section{Yu-Sung Lee MD}

Wei-Jing Lee MD

Emergency Medicine

Chi-Mei Medical Center

Yung-Kang City

Tainan, Taiwan

Competing interests: None declared.

\section{REFERENCES}

I. Lal SK, Morgenstern R, Vinfiraver EP, et al. Sig moid volvulus an update. Gastrointest Endosc Clin N Am 2006;16:175-87.

2. Ballantyne GH, Brander MD, Beart RWJ, et al. Volvulus of the colon: incidence and mortality. Ann Surg 1985;202:83-92.

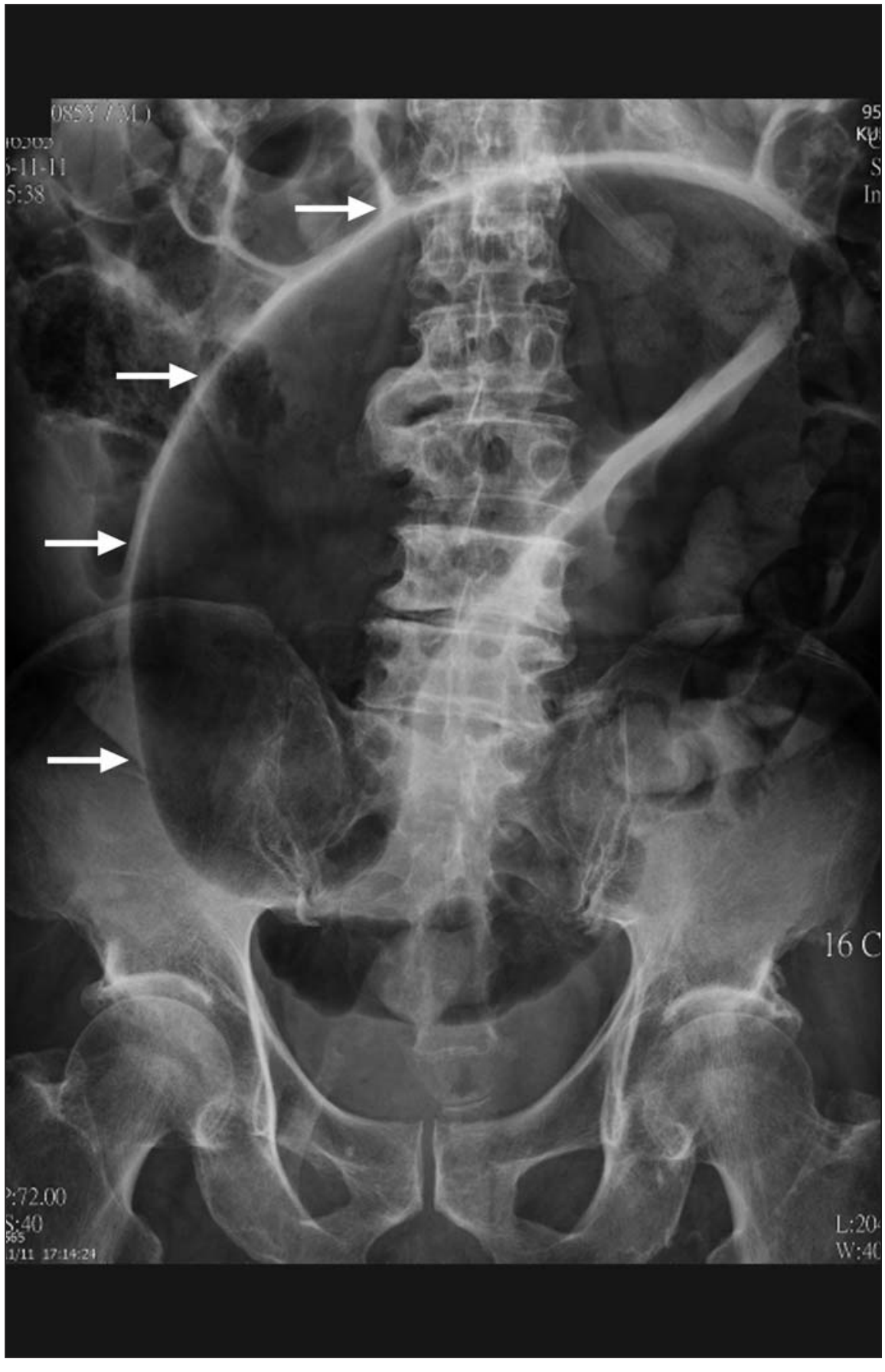

Figure 1: Plain radiograph of the abdomen of an 85-year-old man showing a markedly dilated sigmoid loop (arrows) with an inverted U-shaped appearance (coffee-bean sign). 